\title{
A importância do conceito de esfera pública de Habermas para a análise da imprensa - uma revisão do tema
}

\author{
Ana Paula Ferrari Lemos Barros ${ }^{1}$
}

\section{Resumo}

O presente artigo revisa os conceitos originais e as reelaborações de Habermas sobre a esfera pública e apresenta as contradições apontadas por críticos que consideram o modelo por demais abstrato e irreal. O presente texto apóia o ideal de que as discussões de temas de interesse público sejam abertas e amplas, e, apesar disso, reconhece que o modelo habermasiano foi desenvolvido com base numa sociedade democrática com alto grau de participação e conscientização de seus cidadãos.

Palavras-chaves: Esfera Pública. Cidadão. Imprensa. Participação.

\section{Introdução}

O filósofo alemão Jürgen Habermas se dedica a compreender as patologias da modernidade e a realização deformada da razão ao longo da história. Ele resgata as origens da esfera pública grega e acompanha suas transformações até o sistema capitalista, tendo a burguesia o papel de ator social, mas reformula seu pensamento a partir de críticas recebidas.

As características principais de seu raciocínio são a defesa e o exercício da crítica e da argumentação. Para Habermas, a razão deve ser usada para promover a interação nos processos sociais e de emancipação humana. O autor busca suas bases em Sócrates, de quem resgata o conceito de auto-reflexão como forma de libertação da tirania e da escravidão de falsas idéias. Habermas (1981) defende a comunicação dialógica como um imperativo prático. Pretende capacitar as novas

\footnotetext{
${ }^{1}$ A autora é doutoranda em Jornalismo e Sociedade pela Universidade de Brasília. Atuou como jornalista no setor de telejornalismo da TV Bandeirantes e TV Nacional. Atualmente, é responsável pela área de Comunicação da Ouvidoria da Anvisa e ministra a disciplina Telejornalismo no UniCEUB.
} 
práticas sociais cotidianas à racionalidade comunicativa e define a racionalidade comunicativa como um instrumento para a construção de um comportamento social mais solidário e livre.

Habermas acredita que é possível enfrentar desafios e reconstruir, de modo responsável, uma perspectiva da modernidade e de suas patologias. Nesse sentido, este artigo visa compreender as bases do conceito de esfera pública e apresentar alguns questionamentos feitos por outros autores.

\section{Desenvolvimento}

Inspirado no conceito da existência humana de Hanna Arendt, Habermas (1961) faz um estudo histórico da polis grega e do comportamento dos cidadãos no exercício da vida pública. Busca no modelo grego a origem histórica do pensamento europeu sobre os conceitos de "público" e "privado". Identifica como esfera pública o espaço do convívio comunitário, onde os cidadãos livres se encontravam para compartilhar, valorizar e transformar a cultura, os esportes, a guerra e as opiniões. Nesse ambiente, a liberdade e a igualdade entre os integrantes eram os pressupostos básicos, condições para a realização da política em seu sentido mais amplo, de discussão e de disputa. Os que se destacavam no uso do discurso e na ação política alcançavam a "imortalidade da fama" (HABERMAS, 1961).

Segundo sua análise histórica, o critério grego para a concessão do direito a participar da esfera pública era o grau de autonomia do cidadão diante das necessidades de sobrevivência. Em oposição ao público, estava o privado, ou o espaço da vida doméstica e familiar, local onde se garantia a sobrevivência. $\mathrm{O}$ surgimento de cidades e a intensificação do comércio propiciaram o encontro de cidadãos livres e a discussão de temas de interesse comum. Habermas descreve e identifica, desde o período feudal, embriões da esfera pública que se desenvolveram na era moderna com a burguesia. Nessa fase, a emergência de uma sociedade civil está ligada à reunião de pessoas privadas para formar um público, com o objetivo de debater questões do Estado, dentre outras. O modo de vida da burguesia favoreceu o debate de idéias, pois valorizava as capacidades intelectuais por oposição às condições de nascimento. 
Com o advento do Estado Absolutista e o desenvolvimento do capitalismo, a esfera pública burguesa se transformou em um ambiente de resistência à autoridade pública estatal. Assim, a sociedade civil se fortaleceu e protagonizou uma tensão entre a cidade e a corte: o privado versus o público. Os cidadãos buscavam esclarecimento sobre os temas antes restritos ao Estado e à Igreja e fizeram circular suas opiniões, criando meios de publicidade como folhetins e pequenos jornais. Um dos temas reivindicados pela burguesia foi o acesso à política. Com o exercício da discussão de idéias, a esfera pública adquiriu a função de legitimação da lei, ou seja, estabeleceu o vínculo entre as normas editadas pela autoridade estatal e a opinião pública.

Habermas reconheceu a formação da esfera pública burguesa como uma instância mantenedora dos interesses coletivos, mas que só estava aberta à participação dos cidadãos que possuíam propriedades e esclarecimento - os burgueses. Por isso, esse ambiente se tornou sujeito aos interesses dessa classe. Apesar das contradições no seio da esfera pública, o autor entendia esse espaço como um lugar onde a expressão e a ação comunicativa podiam favorecer uma consciência coletiva capaz de possibilitar uma existência solidária, não coercitiva, libertadora e igualitária entre os homens.

Lavina Ribeiro (2004b) considera que a esfera pública se desenvolveu movida pela luta dos burgueses para a transformação do Estado absolutista em Estado burguês. Para a autora, as mudanças foram fortalecidas pelo engajamento de instituições como os partidos políticos e a imprensa.

Nesse contexto, os meios de difusão ou de publicidade assumiram o papel de mediação, possibilitando o diálogo entre a burguesia, as outras classes que foram surgindo e o Estado. Assim, a luta entre classes pelo poder se tornou concreta pelas ações partidárias e críticas ao Estado veiculadas pela imprensa.

\section{As críticas}

Ao expor a concepção de esfera pública, Habermas (1961) influenciou vários trabalhos, mas recebeu diversas críticas. Serra (2001) compilou alguns aspectos da abordagem crítica: a inadequação histórica do conceito; a 
subestimação do fato de que embora idealmente universal a esfera pública burguesa excluía as mulheres, os pobres, os não educados e as minorias étnicas; o não reconhecimento do papel das esferas públicas alternativas formadas, por exemplo, pelo movimento operário; o excessivo racionalismo do conceito e a separação rígida entre esfera pública e privada e, na fase do capitalismo tardio, a atribuição de um papel por demais negativo aos meio de comunicação de massa e por demais passivo à audiência.

Percebe-se que as críticas se concentraram na desigualdade de acesso à esfera pública. Com isso, alguns autores reduziram o modelo habermasiano ao aspecto dialógico, com base na comunicação interpessoal, julgando-o ultrapassado pela complexidade da comunicação contemporânea. Outros propuseram a sua validade como padrão normativo ou crítico - um ideal. Maia (2006) menciona a confusão gerada com a apropriação do termo "esfera pública" para definir até mesmo os meios de comunicação de massa. A autora esclarece que a mídia disponibiliza expressões, discursos, imagens e eventos para o conhecimento comum, mas a possibilidade de acesso aos seus canais e a seleção de tópicos são fortemente regulados pelos agentes do próprio sistema. Portanto, não se configura como um espaço aberto, acessível à discussão. Para Maia, não se pode confundir a 'visibilidade’ produzida pela mídia com a concepção de esfera pública.

O espaço de visibilidade midiática ou cena midiática é o conteúdo disponibilizado pelos meios de comunicação para o conhecimento comum, já a esfera pública é o ambiente da argumentação (GOMES, 1999). No entanto, Maia defende a complexidade e o potencial ambíguo dos meios de comunicação ao produzirem uma esfera de debate interna ao espaço de visibilidade com funções além das de fórum. Segundo a autora, os meios de comunicação têm o papel de "vigilante" das instituições sociais e estatais e de mobilizador.

Outro crítico de Habermas, Schudson (1992), rejeita em parte o conceito de esfera pública e defende que não se trata de um espaço, mas um conjunto de atividades que constituem a auto-reflexão e o autogoverno numa sociedade democrática. Esse conceito, segundo Schudson, é diferente na Europa do Leste dos anos 1980 e nas democracias liberais. Nessa última, a sociedade civil não é necessariamente oposta ao Estado. Essa oposição se dá em momentos específicos, quando falham as esferas mediadoras, nas quais a sociedade pode participar da tomada de decisões. 
O autor identifica que, no Estado Moderno, a esfera pública se processa nas eleições (processo que confere aos eleitos o direito de tomarem decisões em nome dos que representam), também nas associações e instituições privadas, onde não há uma distinção entre governo e iniciativa privada ou setor público e privado. Schudson (1992) não aceita a definição de esfera pública como sociedade civil relativa à vida privada. Para ele, a sociedade civil é formada por instituições intermediárias entre o Estado e as pessoas privadas (Igreja, meios de comunicação, partidos políticos e associações). $\mathrm{O}$ autor defende que o Estado deve ser inserido dentro da esfera pública, mas não como dimensão separada da vida social.

Portanto, o autor insere o Estado no centro da análise como promotor da sociedade civil e da esfera pública. Mas reconhece que o governo alterna posturas de apoio e desencorajamento em relação às associações de cidadãos. Para ele, há uma influência mútua, pois as instituições da sociedade civil estão simultaneamente dentro e fora do Estado e argumenta que formas de representação darão origem a determinados tipos de espaço público. Com a existência da imprensa livre, o eleitor, por exemplo, poderia conhecer o caráter e a conduta dos eleitos e ter informações para identificar difamações políticas. No contexto europeu, Schudson (1995) classifica a mídia como uma esfera de governo, diferentemente da realidade americana, em que a mídia possui, segundo o autor, um grau maior de separação do governo, mas que mesmo assim é historicamente variável. Por fim, admite que não há uma linha divisória clara entre o Estado e a imprensa privada.

As críticas provocaram a reflexão de Habermas e contribuíram para a reelaboração de conceitos. O autor reapresentou a noção de esfera pública, considerando sua função normativa e defendendo sua validade empírica.

\section{Avanços na esfera pública}

A proposta original percebia a esfera pública como um fórum para a formação da opinião pública. Habermas reconheceu que esse espaço entrou em declínio pelo desenvolvimento da publicidade e estratégias de mercado que intensificaram o caráter comercial dos meios de comunicação de massa e pela amenização da 
dicotomia entre o público e privado devido às ações do Estado de bem-estar social. $\mathrm{O}$ autor abandonou, portanto, o modelo bipolar que colocava a sociedade civil em contraposição ao Estado, e optou pela consideração de diversos públicos ou arenas discursivas espalhados pela sociedade. A esfera pública passou a ser o lugar de conflito entre diferentes grupos de interesse que procuram a mídia para manipular a audiência, ou o público. O termo "público" aqui pode ser empregado para referirse a fenômenos distintos, como algo aberto e disponível a todos (visibilidade); algo potencialmente concernente a todos (de interesse comum) e como uma reunião de pessoas, ou audiência (ASEN; BROUWER, 2001).

$\mathrm{Na}$ revisão do conceito, Habermas (1997) descreve a esfera pública ou espaço público como o espaço de discussão, fundamentado na capacidade de confrontar argumentos racionais com a opinião baseada na razão. A soberania do povo, em sociedades complexas, passou a ser entendida como um processo prático de argumentação, fruto da interceptação e sobreposição de discursos. No entanto, não pode se impor apenas por discursos públicos informais. Para gerar poder político, a influência dos cidadãos tem que produzir efeito nas deliberações democráticas, assumindo uma forma autorizada. O público, portanto, depende de garantias providas pelo Estado para exercer sua liberdade comunicativa. Necessita de condições de participação igualitária em processos legislativos democráticos (participação em partidos políticos e votações na tomada de decisões das instituições parlamentares). As preferências dos cidadãos e a possibilidades de escolha não são estáticas, mas constantemente modificadas pelo debate público ou processo político. $\mathrm{O}$ autor defende que somente o poder gerado comunicativamente é capaz de se legitimar.

Assim, como entende Fraiser (1992), há “públicos fortes” (representantes com acesso autorizado ao sistema político) e "públicos fracos" (os cidadãos que produzem a opinião pública). Entre eles ocorre um intercâmbio constante que pode resultar em modificações das decisões. Por meio desse modelo de circulação de poder político de mão dupla, Habermas procura demonstrar que o público deliberante pode interferir nas tomadas de decisão, particularmente em situações de crise.

Na reformulação do conceito, a esfera pública assemelha-se a uma rede para a comunicação de conteúdos, tomada de posição e opiniões. Nela, as manifestações 
são relativas a temas e a posição é a favor ou contra. Informações e argumentos são apresentados na forma de opiniões. Essa rede é altamente complexa e se ramifica em arenas internacionais, nacionais, regionais ou locais que se interagem. Os públicos diferenciados e segmentados por temas, interesses e níveis de organização conseguem, em determinados momentos, dialogar por terem uma linguagem comum e por estarem integrados pelos meios de comunicação (HABERMAS, 1997).

A opinião pública é resultado da avaliação de opiniões que conseguiram influenciar o sistema político, ou seja, de uma prática comunicacional que racionalizou argumentos e contra-argumentos. Forma-se, na esfera pública, um campo de batalha pela influência, num sentido amplo, onde estão presentes discursos de autoridades, artistas, intelectuais, além de movimentos sociais e da Igreja.

A esfera pública não é mais um agregado de indivíduos que formam o público, mas formada por grupos auto organizados em uma arena para a exposição de problemas que necessitam ser elaborados pelo sistema político. Portanto, não é uma instituição, organização, ou sistema. Não regula, pois não tem uma estrutura normativa. Caracteriza-se pela sua abertura, por ser permeável e se deslocar, sendo um fenômeno social. Todos os assuntos são tidos como passíveis de debate na esfera pública, desde que ganhem status político de um tema de interesse geral. Podem ser debatidos temas como a definição de regras comuns e de metas pragmáticas, considerações de justiça, problemas de identidade e autoentendimento cultural, processos de monitoramento das autoridades e prestações de contas.

O conceito ganhou amplitude, praticidade e atualização. Não está mais preso a uma data ou momento histórico. A esfera pública chega a ser definida como qualquer encontro que não se limite a contatos de observação mútua, mas que se alimente da liberdade comunicativa que uns concedem aos outros; movimenta-se num espaço público, constituído por meio da linguagem.

Serra (2001) reconhece como o grande salto qualitativo nessa revisão é a centralidade dada ao conceito de sociedade civil, ao novo papel atribuído aos movimentos sociais, à mídia e à opinião pública. A sociedade civil foi definida como o conjunto organizado de associações emergentes de forma mais ou menos espontânea ou organizações e movimentos que conectados ao reflexo dos 
problemas nas esferas da vida privada destilam e transmitem essas reações de forma ampliada na esfera pública (HABERMAS, 1997).

Desta forma, os meios de comunicação de massa passaram a ser vistos com potencial para desempenharem um papel mais político e positivo e a audiência exercer o julgamento crítico, a partir de esferas públicas mais autônomas que restrinjam o poder da mídia. Já na teoria do agir comunicativo, Habermas (1981) abandona a visão dos meios de comunicação meramente a serviço da reprodução da ordem social (como agentes de manipulação ou porta-vozes de grupos poderosos, infensos à participação democrática) e reconhece a ambigüidade de seu papel social. Percebe a construção de um espaço, temporalmente mais amplo à comunicação e disponibilização de conteúdos para vários contextos. $\mathrm{O}$ autor sustenta a possibilidade de a mensagem transmitida pela mídia produzir um processo reflexivo crítico por parte da audiência.

Na revisão do conceito, Habermas (1997) classificou três tipos de esfera pública, sendo uma especificamente produzida pela imprensa: a esfera pública abstrata. Nesse espaço, a mídia trabalha de forma a conectar públicos diversos e espalhados geograficamente. Apesar disso, reconhece que a agenda ou o conteúdo da mídia são conduzidos por atores institucionais poderosos e estão quase inacessíveis a atores coletivos de fora do sistema político ou que não pertencem a grandes corporações. No entanto, em situações de crises sociais, a esfera pública, ao se tornar alvo dos atores da sociedade civil, pode desempenhar um papel mais crítico e ativo e, diante das dificuldades estruturais, transformar o fluxo de comunicação e poder.

\section{Conclusão}

Serra (2001) atribui à noção de esfera pública as vantagens da abordagem histórica e a ligação entre a política democrática com a comunicação pública. Já Habermas (1997) identifica como papel da comunicação a formação de identidades, comportamentos e sociabilidades. Assim, a comunicação pode agir para a construção e transformação de espaços públicos e ampliar o conceito de sociedade, cidadania e subjetividade, portanto, o de esfera pública. Além disso, como as audiências ou públicos, os jornalistas são influenciados 
pelas condições culturais, econômicas e políticas, mas também utilizam o seu senso crítico para responder a essas pressões. Atualmente, uma das visões mais aceitas sobre a mídia é a de um campo de conflito entre fontes que representam interesses opostos. Por isso, a análise das fontes de informação que têm seus discursos publicizados pela imprensa é fundamental. Outro aspecto que deve ser levado em conta nas análises empíricas são as conseqüências da visibilidade de alguns atores na imprensa. Por meio dessa exposição, muitos adquirem privilégios quanto a questões de acesso à esfera pública e à representação.

Maia (2006) defende que a proposta de Habermas deve ser entendida como uma situação ideal, na qual, todos os argumentos recebem considerações e os participantes estão dispostos a rever suas opiniões iniciais, sem o exercício de coações e com o objetivo de se chegar a um entendimento. $O$ processo deveria por natureza ser livre de restrições de tempo ou da necessidade de se tomar decisões. Nesse sentido, Habermas estabeleceu parâmetros para se avaliarem debates de temas de interesse público quanto ao grau de democratização:

1. Racionalidade - as preferências devem ser justificadas por meio de argumentos.

2. Expectativa de que os participantes questionem e superem suas preferências iniciais.

3. Inclusividade - todos devem poder participar.

4. Igualdade - os envolvidos no debate devem trocar opiniões na condição de sujeitos livres e iguais moral e politicamente.

5. Não coerção entre os participantes - argumentos devem se sustentar por suas qualidades.

6. Não restrição de tópicos - qualquer tema pode ser publicamente relevante.

7. Revisibilidade de decisões - processo contínuo.

Schudson (1995) defende uma discussão séria e pressupõe regras básicas de que não há neutralidade em nenhum campo de ação. Dessa forma, contribui para o amadurecimento do debate, principalmente por alertar que não basta que 
instituições permitam a livre discussão de assuntos políticos. É preciso atribuir poder na tomada de decisões. O voto seria uma forma de expressar essa opinião e provocar mudanças. No entanto, para ser eficaz, é preciso a capacitação do público, ou seja, a qualificação dos participantes.

Maia lembra que as restrições são inerentes aos debates e enumera constrangimentos como a ausência de status igual entre os participantes; falta de preparo para a reflexão e ponderação de assuntos de interesse coletivo; falta de interesse em ouvir os outros argumentos; falsificação de argumentos e indisposição a alterar os próprios pontos de vista, além do custo da decisão: o tempo e esforço para se chegar a um acordo ou consenso. Diante de variáveis, a autora recomenda a execução de projetos empíricos de pesquisa para perceber como o modelo de caráter abstrato pode ser aplicado à realidade social. Maia aponta, como fator positivo no pensamento habermasiano, o esforço em se explicar como os cidadãos podem interferir nos processos de governança. Resta saber se esse conhecimento já chegou ao Estado, à sociedade civil e à imprensa e compreender as ações que ambos têm produzido para um processo mais democrático de decisões.

Os critérios elaborados por Schudson (1995) na definição de uma esfera pública devem ser observados por pesquisadores ao estudar a porosidade de instituições sociais como a imprensa. A existência de um fórum representativo de discussão pública com infra-estrutura de recursos de apoio é fundamental para a formação de um juízo público crítico.

\section{The importance of the concepts developed by Habermas for the transformation of the Press - a revision of the theme.}

\section{Abstract}

The present article revises the original concepts and Habermas' rethinkings on the public sphere. It presents the pointed contradictions by the critics that consider the model too much abstract and unreal. The present text supports the ideal of the public interesting themes discussions to be opened and extensive. Inspite of this, it recognizes that the habermasian model was developed with a based in a democratic society with a high degree of participation and awareness of its citizens.

Keywords: Public sphere. Citizen. Press. Participation. 


\section{Referências}

ARENDT, H. A condição humana. Rio de Janeiro: Forense Universitária, 1983.

ASEN, R; BROUWER, D. Counterplublics and the State. State University of New York, 2001.

BERNSTEIN, R. Introdução. In: GIDDENS, A. et al. Habermas y la modernidad. 3. ed. Madrid: Catedra, 1994. (Colección Teorema).

FRASER, N. Rethinking the Public Sphere: a contribution to the critique of actually existing democracy. In: CALHOUN, Graig. Habermas and the public sphere. Cambridge: MIT Press, 1992. p. 109-142.

GOMES, W. Esfera pública política e media II. In: RUBIM, A. A. C.; BENTZ, I. M. G.; PINTO, M. J. (Ed.), Praticas discursivas na cultura contemporânea. São Leopoldo: Unisinos, 1999.

HABERMAS, J. Direito e democracia: entre facticidade e validade. Rio de Janeiro: Tempo Brasileiro, 1997.

. Teoria de la acción comunicativa. Madrid: Taurus, 1981. Traducido do original: Theorie dês Kommunikativen handelns, Frankfurt. Tradução para o espanhol.

. Mudança estrutural da esfera pública: investigações quanto a uma categoria da sociedade burguês. Tradução de Flávio R. Kothe. Rio de Janeiro: Tempo Brasileiro, 1984.

MAIA, R. Democracia deliberativa e tipologia de esfera pública. In: ENCONTRO ANUAL DA COMPÖS, 15., 2006, Bauru. Anais... Bauru, 2006. p. 1-25.

RIBEIRO, L. Comunicação e comunidade: teoria e método. Comunicação e Espaço Público, [S.1], ano VII, n. 1/2, 2004a.

. Comunicação e sociedade: cultura, informação e espaço público. Rio de Janeiro: E-Papers, 2004b.

Comunicação, cultura e cidadania no Brasil. Comunicação e Espaço Público, [S.l], ano IV, n. 2, 2001. 
SERRA, S. A produção de notícias e a esfera pública internacional. In: FAUSTO NETO, Antonio et al. (Org.). Práticas midiáticas e espaço público. Porto Alegre: EDIPUCRS, 2001. v. 1. p. 83-112.

SHUDSON, M. A Esfera Pública e os seus problemas: reintroduzir a questão do estado. Revista de Comunicação e Linguagens, [S.1], 1995. p. 149-166.

. Was there ever a public sphere? If so, when? Reflections on the American case. In: CALHOUN, Graig Habermas and the public sphere. Cambridge: MIT Press, 1992. p. 143-163. 